\title{
O PODER DE NOMEAR E AS CLASSIFICAÇÕES NO DOMÍNIO DAS HOMOSSEXUALIDADES MASCULINAS E MODALIDADES ALTERNATIVAS DE SEXUALIDADE NO BRASIL
}

Francisco Arrais Nascimento ${ }^{1}$, Luis Fernando Herbert Massoni ${ }^{2}$, Rafael da Silva Shirakava ${ }^{3}$, Daniel Martinez-Ávila ${ }^{4}$, Fabio Assis Pinho ${ }^{5}$

1 orcid.org/0000-0003-4424-8844, Programa de Pós-graduação em Ciência da Informação da Universidade Estadual Paulista Júlio de Mesquita Filho, Marília, São Paulo, Brasil. E-mail: francisco.arrais.nascimento@gmail.com

2 orcid.org/0000-0001-6402-1036, Programa de Pós-graduação em Comunicação da Universidade Federal do Rio Grande do Sul, Porto Alegre, Rio Grande do Sul, Brasil. E-mail: luisfernandomassoni@gmail.com

3 orcid.org/0000-0002-1945-7006, Programa de Pós-graduação em Psicologia Clínica da Universidade Estadual Paulista Júlio de Mesquita Filho, Assis, São Paulo, Brasil. E-mail: rafael.2015.shirakava@gmail.com

4 orcid.org/0000-0003-2236-553X, Departamento de Ciência da Informação da Universidade Estadual Paulista Júlio de Mesquita Filho, Marília, São Paulo, Brasil. E-mail: dmartinezavila@marilia.unesp.br

5 orcid.org/0000-0003-1346-3808, Universidade Federal de Pernambuco, Recife, Pernambuco, Brasil. E-mail: fabiopinho@ufpe.br

Tipo de contribuição: comunicação

Palavras-chave: Domínio das Homossexulidades; Classificação; Modalidades Alternativas de Sexualidade; Autonomeação; Autoclassificação.

\section{Introdução}

O conceito de biopolítica proposto por Foucault ancora-se em dois eixos: a anatomopolítica disciplinar do corpo humano e os controles regulatórios da biopolítica da população (Castro, 2011). Eles arraigam-se em um conjunto de "dispositivos" que suscitam a percepção de discursos hegemônicos que regulam e instauram normas, produzem "verdades" e assim prevalecem e são perpetuados (Foucault, 2000). Logo, a sexualidade e a própria construção social do sexo configuramse como dispositivos disciplinares e biopolíticos que se instauram enquanto técnicas políticas necessárias para o governo das massas, ajustando-as à dinâmica da produção e do consumo em ascensão na sociedade capitalista, onde a vida "[...] só é útil porque é, ao mesmo tempo, sã e dócil, ou seja, medicalizada e disciplinarizada" (Revel, 2006, p. 55-56).

Adentrar ao domínio das sexualidades enquanto dispositivo (Foucault, 1988) permite compreendê-las enquanto campo onde o poder disciplinar e a biopolítica entrelaçam-se em uma estratégia de controle simultaneamente individualizante e massificador (Foucault, 1988; 2000). Logo, concebe-se que toda construção, seja de um sujeito ou de uma identidade, envolve certo grau de normatização, cujo efeito é a produção de excluídos (Miskolci, 2009), revelando-se a intenção de criar corpos sexuados e neles inserir a "natural binaridade" (masculino e feminino), onde ancora-se a gênese de uma realidade baseada na negação, consolidando estereótipos que certificam o padrão heteronormativo de masculinidade e/ou feminilidade (Badinter, 1993). No entanto, a sexualidade é o 
comportamento humano menos natural, pois sendo os caminhos da sexualidade constituintes de formas de expressão, de prazer, de visibilidade e de relação social, estão recobertos de símbolos, rituais e valores que estruturam e dão coesão às práticas e instituições sociais (Prado \& Machado, 2008).

Rich (1993) e Butler (2002) afirmam que a heteronormatividade é uma "ordem compulsória" que exige dos sujeitos uma coerência total entre um sexo, um gênero e uma conduta/desejo/afeto, que são obrigatoriamente heterossexuais. Percebe-se assim, que a coerência do gênero se realiza na criação da ilusão do que seria "natural" para o corpo sexuado e do que pareceria "natural" para aqueles que afirmam ter esse corpo por agirem assim. Logo, "[...] o gênero não é uma performance que um sujeito anterior elege para realizar, mas o gênero é performativo, no sentido em que constitui como efeito o sujeito que pretendo expressar" (Butler, 2007, p. 24). Aqueles que não se adequam a essa ordem são alocados na zona de exclusão, tornando-se ininteligíveis como pessoa porque a identidade só pode ser estabelecida dentro das "[...] leis que buscam estabelecer as linhas causais ou expressivas de conexão entre sexo biológico, gêneros constituídos culturalmente e a 'expressão' ou 'efeito' de ambos nas manifestações do desejo sexual nas práticas sexuais” (Butler, 2007, p. 72).

Butler (2002) define tais sujeitos como corpos abjetos, aqueles cujas vidas são consideradas ilegítimas e, portanto, quase impossíveis de se materializar, destacando ainda que o corpo abjeto "[...] não se restringe de modo algum a sexo e a heteronormatividade. Relaciona-se a todo tipo de corpos cujas vidas não são consideradas, vidas" e "[...] cuja materialidade é entendida como, não importante" (Prins \& Meijer, 2002, p. 161). Assim, compreende-se que toda política identitária é "antidiversitária", uma vez que a identidade não apenas não comporta, mas sim segrega toda e qualquer singularidade. Logo, toda diferença é uma (des)identidade, uma vez que, ou o sujeito adota a moral da identidade ou a ética da diferença. Diante disso, objetiva-se compreender as autonomeações praticadas em aplicativos de relacionamento de forma a esboçar uma classificação do domínio das homosexualidades masculinas, modalidades alternativas de sexualidade e de desejo no Brasil. Tal classificação é desenvolvida não por especialistas, mas sim pelos próprios sujeitos (classificação natural), como um ato de autoempoderamento que influencia de forma direta as representações dos sujeitos, uma vez que, se o que fora construído sobre e em torno das homossexualidades alinha-se sobre a tríade pecado-crime-doença, tal prática configura-se como um rompimento com as linhas componentes dos dispositivos que punem os desvios da norma vigente, constituindo uma relação de saber/poder. Esta classificação e as bases teóricas que a sustentam são consistentes com anteriores estudos de representações de desejo queer em aplicativos e sites online (Keilty, 2012a; 2012b; 2013) onde se indicava que a disciplina social entre os membros de determinadas subculturas sexuais contribuem na construção destas classificações, refletindo muitas vezes a nomenclatura das temáticas, sujeitos e desejos nas subculturas em uma complexa relação com a cultura dominante.

\section{Metodologia}

Estudo qualitativo de cunho documental, apoiado em pesquisa bibliográfica, sob a forma de cartografia. A mesma se constrói à medida que os afetos se manifestam, criando um território e, consequentemente, uma paisagem psicossocial cartografável (Rolnik, 1989; Guattari \& Rolnik, 1996). Compreende-se que os objetos de análise carregam em si sua própria teoria. Se teoria é cartografia, tentou-se compreender as estratégias de manifestação do desejo no campo social.

O corpus da pesquisa fora cartografado utilizando o Scruff (aplicativo mobile de interação social utilizado por homens que buscam relacionar-se afetivo-sexualmente com outros homens), recorrendo-se à técnica de Mineração de Textos por meio do software Voyant Tools, permitindo a visualização de correlações, coocorrências, fluxos e dispersão de temáticas textuais. A ferramenta utilizada para este estudo foi a nuvem de tags, compreendendo o corpus de 1.732 palavras extraídas de 1.005 títulos de perfis de usuários. 
Utilizou-se da técnica de análise de conteúdo (Bardin, 2011) para identificação dos principais assuntos contemplados no corpus, alocando as categorias identificadas (Figura 3). Ressalta-se que as heterossexualidades foram incorporadas ao estudo, em função da própria construção social. Compreende-se que a diferença não atua isolada da norma, mas estabelece uma relação simbiótica onde uma não pode existir sem a outra, pois a posição de uma é certificada pela outra.

\section{Análises e Resultados}

No mundo virtual cria-se um espectro, uma performance que se ancora no desejo. Tal entendimento engloba a compreensão de si, onde "[...] compreender a si mesmo e [...] arquitetar a sociabilidade através da compatibilidade afetiva" (Illouz, 2011, p. 110) é um elemento essencial, uma vez que "[...] a vigilância e a censura da sexualidade orientam-se, fundamentalmente, pelo alcance da "normalidade"” (Louro, 2010, p. 80). Logo, "[...] o segredo ainda parece para muitas pessoas uma estratégia para viver seu desejo" (Pelúcio \& Duque, 2010, p. 10).

Esse entendimento descortina-se por meio dos termos adotados pelos sujeitos para se autoidentificar (Figura 1), onde o "poder de nomear" do indexador (Olson, 2002) é vivificado, refletindo estruturas de valores, impostos pela norma. Hall (1999) lembra que a identidade é uma construção cultural formada no interior da representação, sempre influenciada pela cultura e formada através de processos inconscientes, não nascendo com o sujeito, mas influenciada pelas suas experiências e perspectivas. Ela é sempre um processo, nunca estando completa, pois se encontra em constante disputa, forjada no âmago de tensões e representações, moldada por discursos e interesses. Ou seja, o uso de termos "desviantes" objetiva uma aceitação social, em um processo no qual a identidade individual molda-se para ser assimilada pela identidade coletiva.

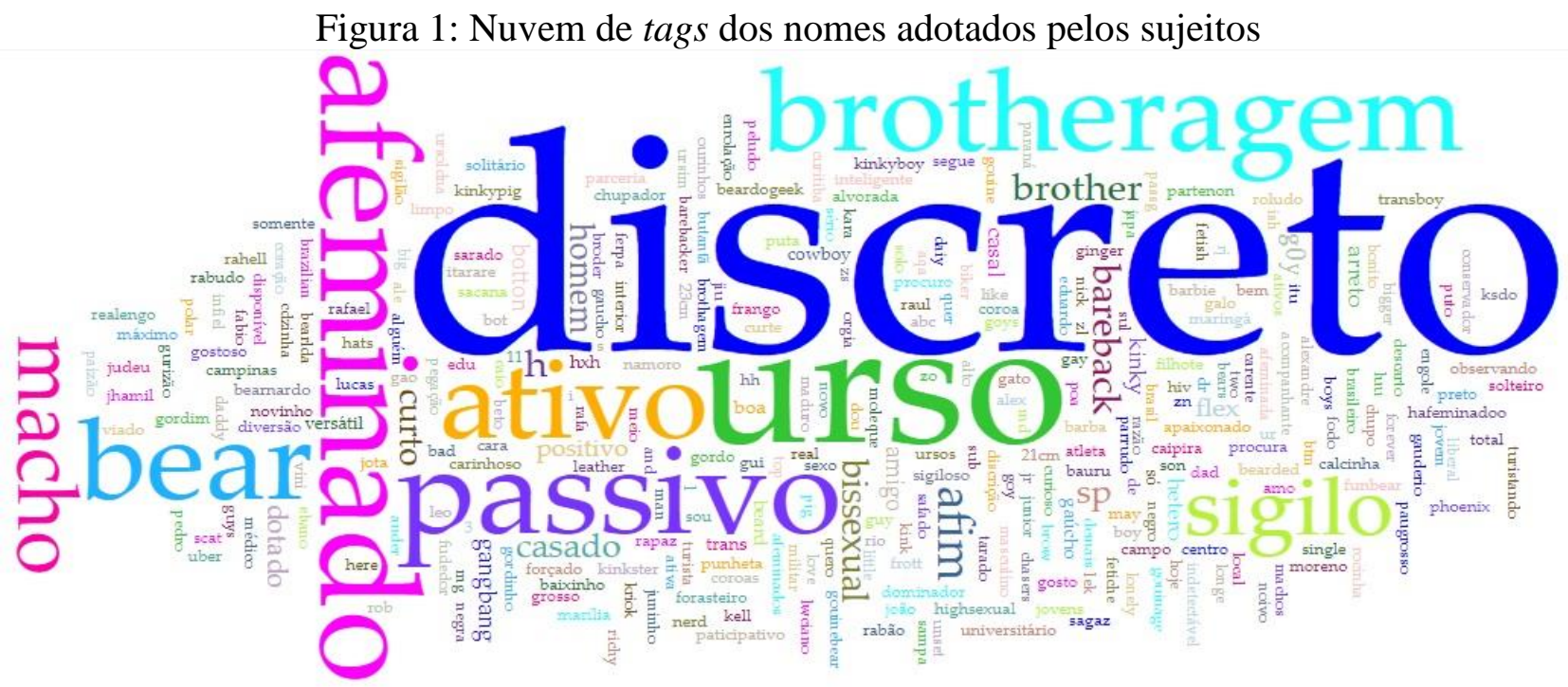

O termo com maior recorrência na amostra é "discreto", objetivando afastar o indivíduo da representação de um homossexual "afeminado", ou seja, assegurar-lhe uma aceitação social devido ao reforço da sua masculinidade, modelo melhor assimilado pela heteronormatividade. Outro termo recorrente e utilizado com o mesmo propósito é "macho", através do qual o sujeito destaca que, embora deseje outros homens, isso não anula sua masculinidade. O termo "brotheragem", adaptação da palavra "brother", representa uma parceria, informando que não busca uma relação amorosa, mas sim uma brotheragem, ou seja, uma parceria masculina para relações sexuais, sem comprometer sua masculinidade e heterossexualidade.

Para Marcuse (2015), a sociedade do pós-guerra "opera" uma espécie de liberdade sexual. Os modelos repressivos, por exemplo, dos tempos de Freud, da Viena fin-de-siécle, foram substituídos 
pela "permissão" da sexualidade, por assim dizer, na qual o corpo é modelado para o trabalho, bem como para o uso de roupas "baratas e atrativas". Nestas condições, faz-se o uso da beleza e da higiene física que transformam corpos em mercadorias: secretárias e vendedoras atraentes, executivos e supervisores musculosos e viris, como apresentados nos catálogos de revistas com o intuito de internalizar nos sujeitos a norma.

O sexo figura enquanto componente do trabalho e das relações públicas, isto é, a libido torna-se uma mercadoria tanto da indústria tecnológica quanto da política. Nesta lógica, incita-se o desejo, numa aparente liberdade que, ao mesmo tempo, gera uma submissão do sujeito às relações de exploração do capitalismo tardio (onde a ideologia e as contradições da realidade estão imbricadas), cujo resultado é a pulverização do protesto e a criação de linhas de fuga como forma de resistência. Frente a isso, essa adaptação identitária torna-se por vezes uma dissonância diante da consonância dos sujeitos produtores de sequencias da linha de montagem do desejo, que são ressignificados através do uso de termos desviantes. Bittar (2009), ao discutir o reconhecimento e o direito à diferença, afirma que os indivíduos não devem ser igualizados, seja pela planificação social ou pela padronização capitalista forjadora do homem unidimensional, pois a pena para essa adaptação pode ser perder-se de si mesmos, de sua auto-identidade, de seus sentimentos, vocações e perspectivas singulares. Bittar (2009) ainda lembra que a linguagem é um aspecto que converge a favor do estranhamento, pois as diferenças assustam pela incompreensão que produzem, gerando medo e exclusão. Logo, por medo da marginalização na qual se pode confinar, sendo possível o comprometimento da própria sobrevivência, quando se ousa criar territórios singulares e independentes das serializações subjetivas; acaba-se reivindicando um território no edifício das identidades reconhecidas (Guattari \& Rolnik, 1996).

Nessa perspectiva, esses sujeitos que buscam relativizar suas práticas sexuais através de termos desviantes, balizam-se na construção social de uma coerência entre um sexo, um gênero e uma conduta/desejo/afeto que produz dobras e sobreposições que se alinham segundo a lógica do sujeito em negociação com a sociedade. Onde se pode vislumbrar a própria essência do lucro capitalista que não se reduz ao campo da mais-valia econômica, mas se estende à tomada de poder da subjetividade, onde o desejo e sua prática tornam-se produtos de uma cultura de massa que produz indivíduos normalizados, articulados uns aos outros segundo sistemas hierárquicos de valores dissimulados (Guattari \& Rolnik, 1996). Acerca da classificação do Domínio das Homosexualidades e Masculinas e Modalidades Alterativas de Sexualidade, Mazzei (1979) esboça uma classificação bem-humorada estabelecendo os sete arquétipos de animais gays que se tornariam a base do atual "reino animal gay" aproximando os sujeitos de animais a partir de características físicas e comportamentais (Figura 2).

Figura 2: Classificação do Domínio das Homossexualidades, segundo Mazzei (1979)

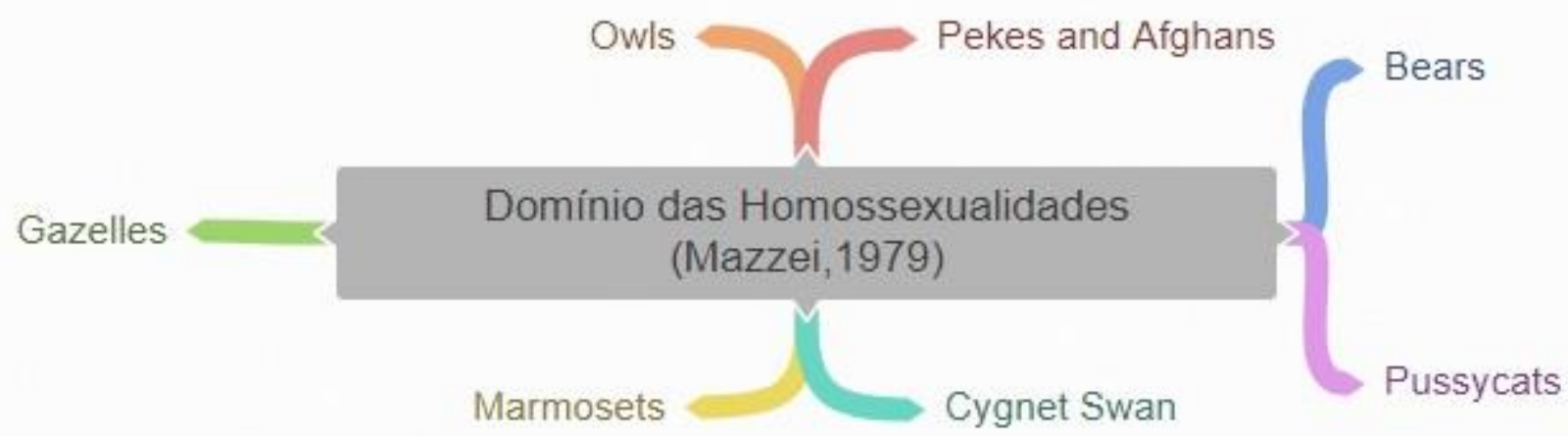

Tal domínio em tempos hodiernos apresenta-se de forma complexa e multifacetada, como se pode observar na representação da classificação elaborada a partir do cospus deste estudo (Figura 3).

\section{Considerações Finais}


A linguagem é um fenômeno sociocultural de expressão, tornando-se êmica de um indivíduo, grupo, classe, um organismo vivo que se transforma com o uso, visando intencionalidades, vontades e desejos. Como identificou-se neste estudo, seja por medo, vergonha ou preconceito, um homem que deseja sexualmente outro homem nem sempre se identifica com o termo "gay", uma vez que essa classificação the renderia estigmas sociais que o mesmo pode não estar preparado para enfrentar. Assim, em sua autoclassificação, alguns sujeitos utilizam termos que provocam deslizamentos de sentido, afastando-os da identidade homossexual e reforçando sua masculinidade, baseando-se em estereótipos e preconceitos.

\section{Referências}

Badinter, E. (1993). XY: sobre a identidade masculina. Rio de Janeiro: Ed. Nova Fronteira.

Bardin, L. (2011). Análise de Conteúdo. Lisboa: Edições70.

Bittar, E. C. B. (2009). Reconhecimento e direito à diferença: teoria crítica, diversidade e a cultura dos direitos humanos. Revista da Faculdade de Direito da Universidade de São Paulo, 104, 551565 .

Butler, J. P. (2002). Cuerpos que importam: sobre os limites materiais e discursivos do sexo. Buenos Aires: Paidós.

Butler, J. P. (2007). El género en disputa. El feminismo y la subversión de la identidad. Barcelona: Paidós.

Castro, E. (2011). Lecturas foucaulteanas. Una historia conceptual de la biopolítica. La Plata: Unipe Editorial Universitaria.

Guattari, F., \& Rolnik, S. (1996). Micropolítica: Cartografias do Desejo. 4 ed. Rio de Janeiro: Vozes.

Foucault, M. (1988). História da sexualidade I: a vontade de saber. Rio de Janeiro: Edições Graal.

Foucault, M. (2000). Sobre a história da sexualidade. Rio de Janeiro: Graal.

Hall, S. (1999). A identidade cultural na pós-modernidade. 3. ed. Rio de Janeiro: DP\&A.

Illouz, E. (2011). O amor nos tempos do capitalismo. Rio de Janeiro: Zahar.

Keilty, P. (2012a). Tagging and Sexual Boundaries. Knowledge Organization, 39(5), 320-324.

Keilty, P. (2012b). Sexual Boundaries and Subcultural Discipline. Knowledge Organization, 39(6), 417-431. 
Keilty, P. (2013). Super Tagging in the Development of Sexual Nomenclature and Social Organization Online. Advances In Classification Research Online, 23(1), 17-20.

Louro, G. L. (2010). Gênero, sexualidade e educação: uma perspectiva pós estruturalista. 11. ed. Petrópolis: Vozes.

Marcuse, H. (2015). O Homem Unidimensional: Estudos da Ideologia da Sociedade Industrial Avançada. São Paulo: EDIPRO.

Mazzei, G. (1979). Who's Who in the Zoo?. The Advocate pp. 42-43.

Miskolci, R. (2009). O armário ampliado: notas sobre sociabilidade homoerótica na era da internet. Revista Gênero, 9(2), 171-190.

Olson, H. A. (2002). The power to name: locating the limits or subject representation in libraries. Dordrecht: Kluwer Academic Publisher.

Pelúcio, L. \& Duque, T. (2010). Homossexualidades, estigmas e o discurso preventivo às DST/AIDS no Brasil ou como os gays deixaram de ser homens que fazem sexo com homens. Anais Seminário Internacional Fazendo Gênero, Florianópolis, SC, Brasil.

Prado, M. A. M., \& Machado, F. V. (2008). Preconceito contra homossexualidades: a hierarquia da invisibilidade. São Paulo: Cortez Editora.

Prins, B., \& Meijer, I. C. (2002). Como os corpos se tornam matéria: entrevista com Judith Butler. Revista Estudos Feministas, 10(1), 155-167.

Revel, J. (2006). Nas origens do biopolítico: de Vigiar e punir ao pensamento da atualidade. In J. Gondra. \& W. Kohan (Orgs.), Foucault 80 anos (pp. 51-62). Belo Horizonte: Autêntica.

Rich, A. (1993). Compulsory heterosexuality and lesbian existence. In B. C. Gelp, \& A. Gelp (Ed.). Adrienne Rich's Poetryand Prose. New York/London: W.W. Norton \& Company.

Rolnik, S. (1989). Cartografia Sentimental: Transformações contemporâneas do desejo. Editora Estação Liberdade, São Paulo. 
Figura 3: Classificação das Homossexualidades Masculinas e Modalidades Alternativas de Sexualidade

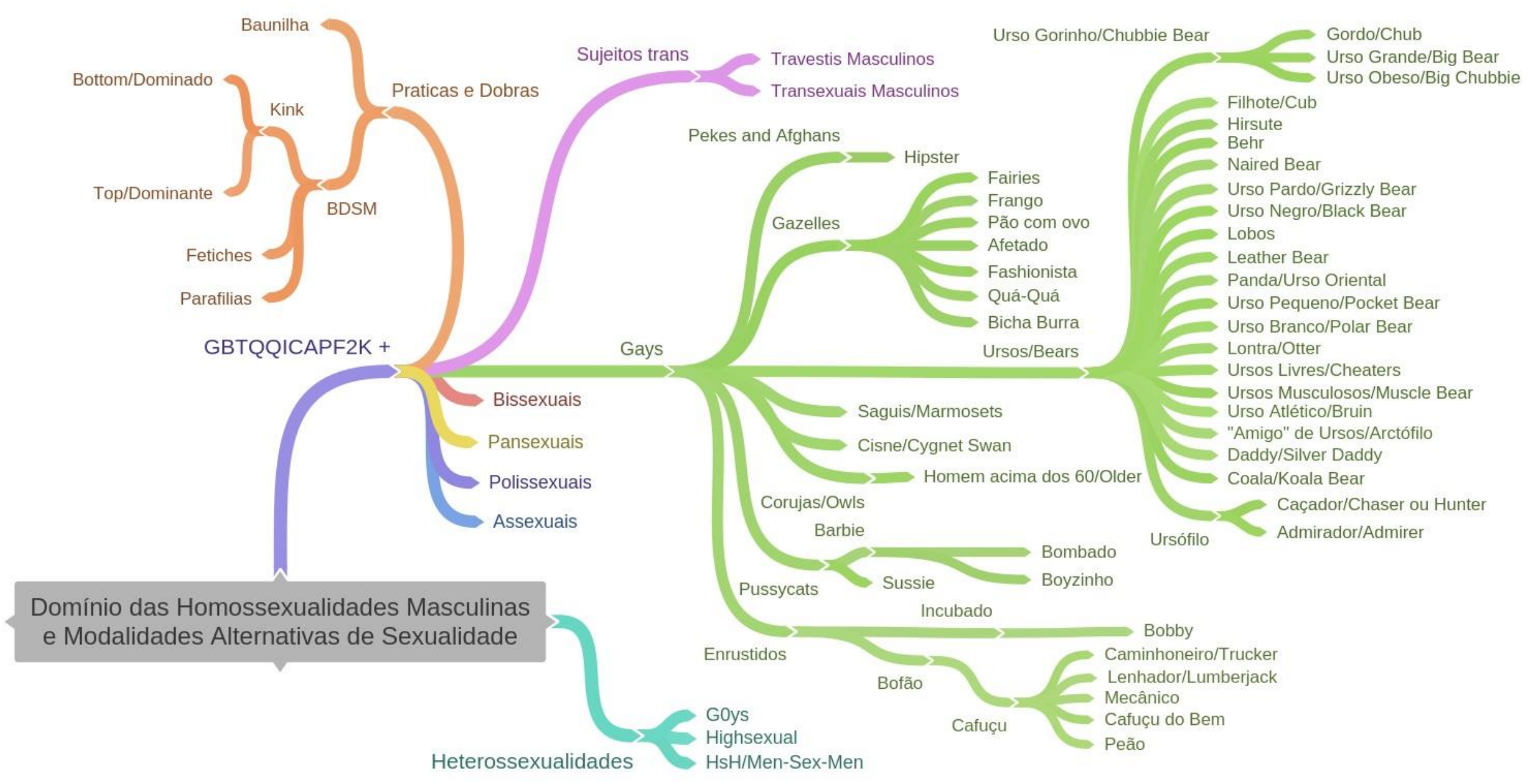

